\title{
Partisanship, Humility, and Epistemic Polarization
}

Thomas Nadelhoffer, Rose Graves, Gus Skorburg, Mark Leary, and Walter Sinnott-Armstrong

This is a prepublication draft. It will be included in M.P. Lynch \& A. Tanesini (Eds.), Arrogance

and Polarization (Routledge, forthcoming)

\begin{abstract}
Much of the literature from political psychology has focused on the negative traits that are positively associated with affective polarization-e.g., animus, arrogance, distrust, hostility, and outrage. Not as much attention has been focused on the positive traits that might be negatively associated with polarization. For instance, given that people who are intellectually humble display greater openness and less hostility towards conflicting viewpoints (Krumrei-Mancuso \& Rouse, 2016; Hopkin et al., 2014; Porter \& Schumann, 2018), one might reasonably expect them to be less polarized.

We ran two studies designed to explore the relationship between various forms of humility and polarization. Our chief finding is that people who value humility are prone to what we are calling epistemic polarization - that is, judging the epistemic traits of contrapartisans negatively-which in turn plays a role in polarization more generally. Not only are contrapartisans deemed to have the wrong moral and political beliefs, they are also viewed as less humble and more arrogant, close-minded, and irrational. This makes matters even worse when it comes to the growing partisan divide. In light of our findings, we believe that the novel concept of epistemic polarization that we introduce is a promising target for further investigation.
\end{abstract}

\section{Keywords}

Partisanship, Humility, Intellectual Humility, Polarization

\section{Introduction}

The gathering evidence makes it clear that the partisan divide in the U.S. is wider now than it has been in forty years (Pew Research Center, 2014; 2017). As a result, many Americans no longer merely disagree with their political opponents, they have animosity toward them (Pew Research Center, 2016). Consequently, researchers have become especially interested in how partisan 
identity in the U.S. has led to affective polarization - the tendency "to view opposing partisans negatively and copartisans positively" (lyengar \& Westwood, 2015; see also lyengar \& Krupenkin, 2018; lyengar, Sood, \& Lelkes, 2012). On this broad definition of affective polarization, copartisans need not have any particular negative affect towards contrapartisans-e.g., hate, disgust, dislike, aggression, etc. Instead, affective polarization merely requires that given some negative affect, people are inclined to view contrapartisans negatively (which often has the downstream effect of creating ideological and social distance). This process can create a polarizing feedback loop: Negative affect leads to the derogation of contrapartisans, which in turn produces negative affect, which leads to further derogation, and so on.

Such affective polarization can take many forms. For example, one might be disposed to view one's own moral beliefs and behaviors and the moral beliefs and behaviors of copartisans positively, while viewing the moral beliefs and behaviors of contrapartisans negatively. Call this moral polarization. One might be similarly disposed to view one's own intellectual traits and the intellectual traits of copartisans positively, while viewing the intellectual traits of contrapartisans negatively. Call this epistemic polarization. What makes both moral and epistemic polarization forms of affective polarization as it is being defined here is that they systematically lead people to derogate contrapartisans. There are probably other kinds of polarization which fall under the heading of affective polarization, but in this paper we will largely be concerned with the epistemic variety of affective polarization. 
Perhaps the two most fundamental questions raised by affective polarization are: What are the various causes of the recent increase in affective polarization ${ }^{1}{ }^{1}$ And what, if anything, can we do to stem its tide? Much of the literature on polarization has focused on negative psychological traits that are positively associated with polarization-e.g., animus, arrogance, distrust, hostility, and outrage. Not as much attention has been focused on positive psychological traits that might be negatively associated with polarization. For instance, given that people who are intellectually humble display greater openness and less hostility towards conflicting viewpoints (Krumrei-Mancuso \& Rouse, 2016; Hopkin et al., 2014; Porter \& Schumann, 2018), one might reasonably expect them to be less polarized. Yet the literature from social science and philosophy has not paid much attention to the potential relationship between humility and polarization.

To fill this empirical lacuna, we ran two studies designed to explore features of personality that might contribute to individual-level polarization. Our key findings were that (a) many people who score high in intellectual humility also value humility, (b) many people who value humility are more inclined to find the virtue lacking in others (especially contrapartisans), and (c) people who exhibit both of these traits are more likely to judge themselves as more epistemically virtuous than members of the other political party. Given that contrapartisans are sometimes judged to be more arrogant and less humble, open-minded, and rational than copartisanswhich we are calling epistemic polarization-our findings shed light on polarization more

\footnotetext{
${ }^{1}$ From here on out, we will use "polarization" and "affective polarization" interchangeably unless we specify otherwise.
} 
generally. We believe that the novel construct of epistemic polarization that we introduce here is an important component of polarization and a promising target for further investigation.

\section{From Partisanship to Intellectual Humility}

Partisanship is defined in terms of not just membership but identification with a political party. Partisanship is thus based on group identity, which involves not only a favored in-group but also disfavored out-groups. In the U.S., most partisans identify with either the Democratic party or the Republican party. Researchers have long known about the dangers posed by in-group favoritism and out-group bias (Campbell et al., 1960; Tafjel, 1970; Tafjel, 1981). Specifically, group identity leads people to systematically derogate contrapartisans, which is a hallmark of polarization. Polarization not only negatively impacts the political domain-making civil discourse and bipartisan legislation more difficult-it also "spills over" into non-political domains. For instance, researchers have found partisan bias in dating behavior (Huber \& Malhotra, 2017), the evaluation of applicants for a college scholarship (Iyengar \& Westwood, 2015), the evaluation of job applicants (Gift \& Gift, 2015), and online labor markets (McConnell et al., 2018). In these and related contexts, polarization creates social distance between partisans, leading them to engage in biased and discriminatory behavior.

Given the negative influence that polarization has on both political and non-political behavior, it is unsurprising that it has received so much attention. A great deal of ink has been spilled trying to identify and isolate the root causes of polarization. Much of this research has focused on the impact of cultural, political, and technological developments such as echo chambers, filter bubbles, social media, and partisan news networks (see, e.g., Lelkes, Sood, \& 
Iyengar, 2017; Pariser, 2011; Sunstein, 2001). Other research has focused on the negative psychological traits associated with polarization, such as anger (Huber et al., 2015), arrogance (Lynch, 2019), disgust (Clifford, 2019), intolerance (Brandt et al., 2014; Crawford et al., 2017) and moral outrage (Crockett, 2017). However, as noted earlier, rather than exploring the negative psychological traits that are associated with higher polarization, our goal was to explore a positive trait that might be associated with lower polarization.

Intellectual humility $(\mathrm{IH})$ focuses on the recognition that one's beliefs might be incorrect. It is an epistemic virtue that has recently received a lot of attention (Church \& Barrett, 2017; Deffler, Leary, \& Hoyle, 2016; Hopkin, Hoyle, \& Toner, 2014; Hoyle et al., 2016; Krumrei-Mancuso \& Rouse, 2016; Leary et al., 2017; McElroy et al., 2014; Porter \& Schumann, 2018; Samuelson et al., 2012; Whitcomb et al., 2017). To help regiment this research, an interdisciplinary team of leading philosophers and psychologists recently adopted a uniform characterization of what it means to be intellectually humble. Specifically, $\mathrm{IH}$ involves the disposition to recognize "that a particular personal belief may be fallible, accompanied by an appropriate attentiveness to limitations in the evidentiary basis of that belief and to one's own limitations in obtaining and evaluating relevant information." ${ }^{2}$ Defined in this way, IH can be expressed in relation to both matters of fact (e.g., science, historical events, personal experiences) and matters of opinion (e.g., politics, religion, sports). In either case, people who are intellectually humble appreciate their epistemic limitations because they realize that their beliefs could be limited, that the evidential basis of their beliefs could be flawed, that they may be missing relevant information,

\footnotetext{
2 See, Leary, M. The psychology of intellectual humility. https://www.templeton.org/wpcontent/uploads/2018/11/Intellectual-Humility-Leary-FullLength-Final.pdf
} 
and that they may lack the expertise and knowledge needed to evaluate a particular piece of evidence (Leary et al., 2017, 794).

That said, we can distinguish between general $\mathrm{IH}$-the overall disposition to be intellectually humble (Leary et al., 2017)-and specific $\mathrm{IH}$-which is focused on particular domains of knowledge (e.g., politics), particular topics within those domains (e.g., immigration), and particular issues within those topics (e.g., building a wall on the southern border of the U.S.) (Hoyle et al., 2016). Someone can score high on general IH but score low on specific IH with respect to a particular domain, topic, or issue (and vice versa). Researchers have designed scales for measuring these two related but distinct types of humility, which we used in our present efforts to explore the relationship between humility and polarization. But before we discuss our studies, we want to say a few words about the interpersonal and intrapersonal benefits of IH.

People who score higher in IH score higher in epistemic curiosity and need for cognition (Leary et al., 2017; Litman \& Spielberger, 2003; Porter and Schuman, 2018) and lower in dogmatism, intolerance of ambiguity, and self-righteousness (Leary et al., 2017). People who are intellectually humble also display greater openness and less hostility towards conflicting viewpoints (Krumrei-Mancuso \& Rouse, 2016; Hopkin et al., 2014; Porter \& Schumann, 2018). More importantly for present purposes, people who score low in IH have more negatively valenced reactions to ideas, information, and people that disagree with them (Hook et al., 2017; Hopkin et al., 2014; Leary et al., 2017; Porter \& Schuman, 2018; Van Tongeren et al., 2016).

For these reasons we wanted to explore the relationship between $\mathrm{IH}$ and polarization. As we suggested earlier, humility seems like precisely the sort of state and trait that might be 
negatively related to polarization. While people who are polarized often seem to be arrogant, contemptuous, dogmatic, and hostile, humble people seem to exhibit the opposite characteristics. So, we wanted to explore the relationship between these two seemingly conflicting constructs. Our original prediction was that the varieties of humility we measured would be straightforwardly negatively correlated with affective polarization. As we will now see, things were more complicated (and more interesting) than we initially expected.

\section{Study 1: A Preliminary Investigation}

\subsection{Methods}

The data set, supplemental materials (which contain all of our stimuli), and complete analyses for Study 1 can be found at our Open Science Framework (OSF) page at: https://osf.io/rk4by/. We recruited 450 participants (with the goal of having 300 after exclusions) using Amazon.com's Mechanical Turk (MTurk) survey platform, and we paid them $\$ 1.50$ for completing the survey. ${ }^{3}$ We only recruited participants who satisfied the following criteria: (a) they had successfully completed at least 500 prior surveys, (b) they had a successful completion rate of at least $98 \%$, and (c) they were in the United States. For present purposes, we were interested only in partisans, so we excluded 117 participants who completed the survey but didn't identify as either Democrat or Republican. We also excluded 37 participants who didn't complete the survey and 21 who failed any one of three attention checks. ${ }^{4}$ Data were then analyzed with the remaining

\footnotetext{
${ }^{3}$ MTurk is an online survey service that enables researchers to recruit and pay for participants for completing surveys of studies. For findings concerning the benefits of using MTurk-including the quality of the data and the improved diversity of the participant pool-see Burhmester, Kwang, \& Gosling (2011); Paolacci, Chandler, \& Ipeirotis (2010); Rand (2012).

${ }^{4}$ The attention checks included two multiple choice items, "If Monday is the first day of the week, what is the third day of the week?" and "If January is the first month of the year, what is the fifth month?" Participants also had to identify the type of animal contained in a photograph we showed them.
} 
275 participants $\left(M_{\text {age }}=36\right.$ years, $S D=10.8$, range $e_{a g e}=[20,77], 40 \%$ females, 81\% Caucasian,

64\% Democrat). Study 1 was approved by the Institutional Review Board at Duke University.

The purpose of Study 1 was exploratory. Our primary prediction was that the measures of humility would be negatively correlated with affective polarization. Given what we know about these constructs, we thought our expectations were on solid theoretical ground. So, we used the following measures to put our prediction to the test:

1. The State Humility Scale (Kruse et al., 2017)

2. The Humility Scale (Wright et al., 2017)

3. The Intellectual Humility Scale (Leary et al., 2017)

4. The Social Vigilantism Scale (Saucier \& Webster, 2010)

5. A "feeling thermometer" measure of affective polarization (Weisberg \& Rusk, 1970)

6. A political animosity measure of affective polarization (Pew Research Center, 2016)

7. A measure of political engagement (Pew Research Center, 2017)

8. Party ID (Democrat, Republican, Independent, No Preference, Something else)

9. Political ideology (from very liberal to very conservative)

10. Basic demographics (age, ethnicity, gender, marital status, education, employment status, income, religiosity)

\subsection{Results}

Given how many measures we included owing to the exploratory nature of this study, it is perhaps no surprise that the results were mixed and sometimes difficult to interpret. Because our primary interest was in the relationship between $\mathrm{IH}$ and polarization, that will be our focus here. ${ }^{5}$ We used two independent measures of affective polarization: (a) the political animosity scale-which includes items such as "Members of the opposite party are more dishonest than my own," and "Members of the opposite party are lazier than my own," ${ }^{6}$ and (b) the feeling

\footnotetext{
${ }^{5}$ You can find average scores from all of these measures and the correlations between them at our OSF page.

${ }^{6}$ It's worth nothing that the items from the political animosity scale (which will be our main measure of affective polarization) comport with the account of affective polarization we adopted from lyengar and colleagues. Many of the items make no mention of negative emotions-not even animosity. Rather, the items express negative
} 
thermometer-which measures the affective distance between how warm people feel toward copartisans and how cold they feel towards contrapartisans. For this latter measure, the greater the distance (that is, the higher the difference score), the more affectively polarized a person is. The findings from Study 1 revealed that political animosity and the feeling thermometer were moderately correlated $(r=.49, p<.001)$.

Scores on the general IH scale $(\mathrm{GIH})$ - which includes items such as "I question my own opinions, positions, and viewpoints because they could be wrong" and "I reconsider my opinions when presented with new evidence" - were negatively correlated with political animosity $(r=-$ $.20, p=.001)$. This finding is consistent with our prediction although the relationship is weaker than we expected. However, we found no correlation between IH and the feeling thermometer scale, which was not in line with our prediction. ${ }^{7}$ Given that $\mathrm{IH}$ was only weakly negatively correlated with political animosity and was not correlated with the feeling thermometer, the relationship between our primary constructs of interest was less antagonistic than we anticipated. We thought we had solid reasons for expecting $\mathrm{IH}$ and polarization to pull strongly in opposite psychological directions. Instead, they are only negatively weakly related if they are related at all. So, the key issue was to figure out how to make sense of what we found.

\subsection{Discussion}

evaluations of contrapartisans' epistemic traits, moral attitudes and beliefs, and behaviors. The animosity is indirectly measured based on how strongly participants agree with statements that derogate contrapartisans. The assumption is that the more negatively participants view contrapartisans, the more animosity they have.

${ }^{7}$ We find this in several places in the data sets for both Studies 1 and 2-that is, either political animosity or feeling thermometer, but not both, will correlate with a humility-related construct. This is not surprising given that the feeling thermometer is a very general and vague measure that merely gets at social distance between contrapartisans whereas some of the items of the political animosity scale are specifically about epistemic virtuese.g., contrapartisan close-mindedness and contrapartisan intelligence. Since political animosity is more closely aligned with our present interests, we will focus primarily on that as our main measure of affective polarization. 
One possibility is that most people who are high in IH also strongly value humility. The more people value humility, the more they may be inclined to find it lacking in others, especially contrapartisans. After all, it is natural for people to view copartisans favorably and contrapartisans disfavorably for a number of different attitudes, beliefs, and behaviors. The psychological pull of this kind of partisanship bias is very strong, often leading to distorted judgments about copartisans and contrapartisans alike (Campbell et al., 1960; Tafjel, 1970; Tafjel, 1981; Tafjel, 1982; Tafjel \& Turner, 1979). Via a process of social-categorization, we naturally divide the world up into "us" and "them." This is a phenomenon that is especially prevalent in the political domain where copartisans and contrapartisans are situated along competing ideological lines. Given how naturally predisposed we are to derogate out-groups, it is no surprise that polarization is a problem in the public sphere.

While we initially thought that humility might partly immunize people from this kind of partisan bias, the results of Study 1 suggest that perhaps we were overly optimistic in this regard. Instead, people who are high in $\mathrm{IH}$ and who value $\mathrm{IH}$ may simultaneously overestimate the epistemic virtues of ingroup members while both underestimating the epistemic virtues of outgroup members and negatively evaluating them for lacking highly valued epistemic traits. We are calling this phenomenon epistemic polarization. This, in turn, can fuel polarization more generally. In this way, the different types of affective polarization (moral and epistemic) may be mutually reinforcing. Not only might contrapartisans be derogated for having a particular moral or political belief, but they might also be negatively judged because of the epistemic attitude they seemingly adopt towards this belief. 
In order to shed empirical light on the relationship between valuing humility and affective polarization, we needed to operationalize people's self-ratings of humility and their ratings of humility in others separately so that we could explore self-other differences when it comes to general and specific $\mathrm{IH}$ and how these differences might relate to polarization. So, our goal in Study 2 was to explore whether valuing humility and epistemic polarization might partly explain the weaker than expected negative relationship between IH and affective polarization in Study 1. We also wanted to design new measures of epistemic polarization to see which of these measures best explained our findings.

\section{Study 2: Investigating Epistemic Polarization}

\subsection{Methods}

The data set, supplemental materials (which contain all of our stimuli), and complete analyses for Study 2 can be found at our aforementioned OSF page. We recruited 450 participants for Study 2 (with a goal of having 300 participants after exclusions) using MTurk and we paid them $\$ 1.50$ for completing the survey. We recruited only participants who: (a) had successfully completed at least 500 prior surveys, (b) had a successful completion rate of at least $98 \%$, and (c) were in the United States. We were again only interested in partisans, so we excluded 122 participants who didn't identify as either Democrat or Republican. We also excluded 8 participants who didn't complete the survey and 2 who failed any one of three attention checks. ${ }^{8}$ Data were then analyzed with the remaining 318 participants $\left(M_{\text {age }}=37.3\right.$ years, $S D=11.6$,

\footnotetext{
${ }^{8}$ We used the same attention checks as in Study 1.
} 
range $_{\text {age }}=[19,75], 38.7 \%$ females, $74.2 \%$ Caucasian, $70.8 \%$ Democrat). Study 2 was approved by

the Institutional Review Board at Duke University.

The purpose of Study 2 was to shed light on the unexpectedly weak negative relationship we found in Study 1 between general $\mathrm{IH}$ and polarization. In order to test whether valuing humility might be related to epistemic polarization and polarization more generally, we dropped several measures from Study 1 that were not pertinent to this question and we added several new measures. First, we included the valuing humility (VH) subscale from Wright et al. (2017), which contains items such as "I find humble people to be very admirable" and "Teaching kids the value of humility is very important to their development." ${ }^{9}$ In addition to again including the GIH scale, which focuses on self-reported IH (henceforth, GIHS), we developed an outgroup version designed to explore people's IH ratings of contrapartisans-the general IH other (GIHO) scale. For the latter, participants were asked how well each of six statements describes typical members of the opposite political party. The answer choices ranged from "not at all like them" to "very much like them." Examples of items include, "They question their own opinions, positions, and viewpoints because they could be wrong," and "They reconsider their opinions when presented with new evidence." Items on the GIHS and GIHO are identical, except for the grammatical changes needed for statements about oneself versus other people.

\footnotetext{
${ }^{9}$ In developing the Humility Scale (which includes the Valuing Humility subscale), Wright et al. (2017) took active steps to exclude items from the scale that were correlated with a measure for social desirability. This is a pressing issue when it comes to self-report measures for desirable traits such as humility. Researchers need to take steps to ensure that responses to the items reflect possession of the dispositional trait itself rather than a mere desire to appear to have the trait. It is common in the scale development literature to try to address this issue by controlling for social desirability. This minimizes the likelihood that impression management strategies are driving people's answers.
} 
In addition to measuring general IH (self and other), we measured specific $\mathrm{IH}$ (SIH: Hoyle et al., 2016) using an abbreviated version of the SIH scale with one domain (i.e., politics) and two topics (climate change and immigration). ${ }^{10}$ For each topic, there were three items: (a) "My views about today may someday turn out to be wrong," (b) "When it comes to my views about I may be overlooking evidence," and (c) "My views about may change with additional evidence." In keeping with our strategy for converting GIHS into GIHO, we created a measure to assess people's judgments of contrapartisans' specific $\mathrm{IH}-$ which gave us measures of self-rated specific humility (SIHS) and of the perceived specific humility of contrapartisans (SIHO). The directions for SIHO were the same as those used for GIHO. Moreover, the pronouns were once again switched from the first person to the third person.

Thus, we created two measures to assess how people rate the $\mathrm{IH}$ of contrapartisans and how people attribute IH specifically about politics to contrapartisans. But we also wanted to add something to our psychometric tool kit that measured epistemic polarization more generally (EPG). For this, we developed seven statements that assess perceptions of contrapartisan arrogance, humility, irrationality, and open-mindedness. Moreover, some items asked for ratings concerning whether contrapartisans value humility (or open-mindedness) and some items asked whether contrapartisans behave humbly (or open-mindedly). Using a 7-point scale ranging from "not at all" to "a great deal," participants were presented with the following questions: ${ }^{11}$

1. How much do typical members of the opposite political party value open-mindedness?

2. How much do typical members of the opposite political party value humility?

\footnotetext{
${ }^{10}$ Our goal in picking climate change and immigration was to be balanced. Climate change is a bigger focus of Democrats, and immigration is a bigger focus of Republicans.

${ }^{11}$ Lower composite scores on this measure indicate that participants are less epistemically polarized, whereas higher scores indicate that they are more epistemically polarized.
} 
3. How much do typical members of the opposite political party act humbly about their beliefs?

4. How much do typical members of the opposite political party act arrogantly about their beliefs? [R]

5. How much do typical members of the opposite political party act open-mindedly about their beliefs?

6. How much do typical members of the opposite political party have values (moral, social, economic, family, etc.) that are different from your own? ${ }^{12}$

7. How much do typical members of the opposite political party have irrational beliefs about politics? $[R]^{13}$

The other measures we used in Study 2 were:

1. A "feeling thermometer" measure of affective polarization (Weisberg \& Rusk, 1970)

2. A political animosity measure of affective polarization (Pew Research Center, 2016)

3. A measure of political engagement (Pew Research Center, 2017)

4. Party ID (Democrat, Republican, Independent, No Preference, Something else)

5. Political ideology (from very liberal to very conservative)

6. Basic demographics (age, ethnicity, gender, marital status, education, employment status, income, religiosity) ${ }^{14}$

\subsection{Results}

The three new measures we designed had excellent interitem reliability: (a) GIHO ( $\alpha=.95$ ); (b)

SIHO ( $\alpha=.95)$; and (c) EPG ( $\alpha=.84)$. As for the relationship between the other constructs, GIHS

and SIHS were unsurprisingly correlated $(r=.44, p<.001)$. However, composite scores on GIHS

were not correlated with political animosity, the feeling thermometer, or EPG (which we didn't

measure in Study 1). Although this isn't what we expected given the results from Study 1, the

earlier correlation we found was admittedly weak, which may explain the discrepancy. Either

\footnotetext{
12 In hindsight, this item was not well conceptualized since it gets at non-epistemic attitudes and values. We ended up removing it from the scale because doing so improved the internal validity of the measure and also because this is the one item that did not strongly correlate with the other items. This left us with a 6 -item measure.

${ }^{13}[\mathrm{R}]=$ Reverse scored items.

${ }^{14}$ As was the case with Study 1, we don't have the space to talk about all of the results. For instance, we won't be discussing political ideology, political engagement, or demographics. Complete data and analyses are available at our OSF page.
} 
way, our initial puzzle persisted because we didn't find the negative correlation we originally expected between GIHS and political animosity.

Relatedly, we also found that composite scores on the three SIHS subscales were negatively correlated with EPG $(r=-.27, p<.001)$, political animosity $(r=-.46, p<.001)$, and the feeling thermometer $(r=-.36, p<.001) .{ }^{15}$ These findings suggest that people who are intellectually humble about politics or about specific political issues (such as climate change or immigration) are less likely to be epistemically or affectively polarized. So, what might explain why we didn't find the negative relationship that we anticipated between polarization and IH more generally? Our hunch was that it is not so much being intellectually humble by itself that explains why humility and polarization don't always pull in opposite directions, but rather, the degree to which people value humility partly explains the inconsistent relationship between the two constructs.

So, our next construct of interest was valuing humility, which correlated with GIHS ( $r=$ $.23, p<.001)$, EPG $(r=.32, p<.001)$, political animosity $(r=.18, p<.001)$, and the feeling thermometer $(r=.19, p<.001)$. Given that we expected valuing humility to play an important role in the relationship between humility and polarization, these relationships are consistent with our expectations going into Study 2. We also found that our primary measure of epistemic polarization (EPG) correlated with political animosity $(r=.58, p<.001)$ and the feeling

\footnotetext{
${ }^{15}$ Individual scores on the three subscales from SIHS negatively correlated with political animosity: (a) politics $(r=$ $.36, p<.001)$, (b) climate change $(r=-.36, p<.001)$, and (c) immigration $(r=-.41, p<.001)$. Scores on these three subscales also negatively correlated with the feeling thermometer: (a) politics $(r=-.31, p<.001)$, (b) climate change $(r=-.27, p<.001)$, and $(c)$ immigration $(r=-.33, p<.001)$. Finally, scores on these three subscales were negatively correlated with epistemic polarization: (a) politics $(r=-.16, p<.003)$, (b) climate change $(r=-.25, p<.001)$, and (c) immigration $(r=-.26, p<.001)$.
} 
thermometer $(r=.43, p<.001)$, and that the latter two measures were correlated with one another $(r=.60, p<.001)$. Finally, we found $(a)$ negative correlations between GIHO and EPG $(r$ $=-.68, p<.001)$, political animosity $(r=-.45, p<.001)$, and the feeling thermometer $(r=-.29, p$ $<.001)$, and (b) negative correlations between SISO and EPG $(r=-.62, p<.001)$, political animosity $(r=-.42, p<.001)$, and the feeling thermometer $(r=-.31, p<.001)$. These findings suggest that people who attribute less IH to others tend to be more polarized (and vice versa).

Taken together, these results supported our idea that valuing humility might be related to polarization. One possible explanation is that people who place a great deal of personal importance on having accurate knowledge and beliefs tend to derogate those who don't seem as concerned with accuracy and truth. To say it differently, people who value IH are not likely to extend that humility to their views about IH. It would be somewhat odd to say "I think it's very important for people to recognize that their beliefs might be incorrect, but I might be wrong about that-intellectual stubbornness or arrogance might actually be better." This is similar to the fact that people who greatly value tolerance are nonetheless rarely tolerant about intolerance. Just as valuing tolerance might lead one to be intolerant of people who don't share that value, so one's humble attitude towards one's beliefs and values might not extend to one's own commitment to humility - that is, one might be ironically steadfast and even dogmatic in one's commitment to the value of humility itself.

So, people who highly value IH might be particularly inclined to feel negatively toward those who appear not to value accuracy and truth. This tendency may be particularly pronounced in partisan contexts because many political ideological differences involve deeplyheld convictions, often with moral underpinnings (e.g., abortion, capital punishment, the use of 
torture, gun control), the kinds of convictions that even the most intellectually humble people are unlikely to question. When faced with a contrapartisan ideology, people frequently conclude that contrapartisans are ignoring the facts, and people who value intellectually humility are more likely to be troubled by those who appear to be closed to the truth.

This hypothesis suggests that people's personal orientation with respect to $\mathrm{IH}-$ their own level of $\mathrm{IH}$ and the degree to which they value $\mathrm{IH}-$ may interact with their beliefs about the $\mathrm{IH}$ of contrapartisans. Specifically, people who are high in $\mathrm{IH}$ and/or who greatly value $\mathrm{IH}$ may harbor greater animosity toward contrapartisans to the extent that they believe that those contrapartisans are low in IH. To test this idea, we focused on two sets of predictors of political animosity. One set reflects people's personal orientation toward IH as measured by the General Intellectual Humility Scale (GIHS) and our measure of the degree to which people value humility (VH). The other set involves three measures of how people perceive others' IH: (a) GIHO-ratings of others' general IH, (b) SIHO-ratings of others' IH specifically with respect to the political domain, and (c) EPG-ratings of others' humility, arrogance, open-mindedness, and irrationality. As described above, these latter three measures are inter-correlated in predictable ways. However, their weak to moderate correlations indicate that each measure clearly assesses distinct features of people's beliefs about other people's IH. So, each measure may add unique insight into political animosity.

A 4-model hierarchical multiple regression analysis was conducted in which the predictor variables were entered in sets to test the hypothesis that people who are high in $\mathrm{IH}$ and/or greatly value IH display greater political animosity when they believe that contrapartisans are low in $\mathrm{IH}$. Model 1 tested the main effects of people's GIHS and VH on political animosity, and Model 2 
tested the interaction between GIHS and $\mathrm{VH}$. Then, having accounted for the influence of people's personal IH and $\mathrm{VH}$, Model 3 tested the main effects of the three measures that assess people's beliefs about other people's IH and epistemic polarization: GIHO, SIHO, and EPG. Finally, and most importantly, Model 4 tested the interactions between people's personal orientations toward IH (GIHS and VH) and their beliefs about others' IH (GIHO, SIHO, and EPG); specifically six interactions were tested: GIHS by GIHO, GIHS by SIHO, GIHS by EPG, VH by GIHO, VH by SIHO, and $\mathrm{VH}$ by EPG.

Model 1 revealed significant effects of general IH (GIHS), $B=-0.179, \mathrm{SE}=.084, \mathrm{t}(315)=-$ 2.107, $\mathrm{p}=.036$, and the degree to which participants valued $\mathrm{IH}(\mathrm{VH}), \mathrm{B}=.280, \mathrm{SE}=.076, \mathrm{t}(315)=$ $3.678, p=.00028$. Political animosity was higher among participants who were lower in IH or who valued IH more highly. Clearly, being intellectually humble and valuing humility related to political animosity in different ways. The interaction of GIHS and VH tested in Model 2 was not significant, $B=-.009, S E=.109, t(314)=-.081, p=.935$

When GIHO, SIHO, and EPG were entered in Model 3, the effects for SIHO and EPG were significant. Specifically, participants who rated contrapartisans as less intellectually humble with respect to political beliefs showed greater political animosity, $B=-.166, \mathrm{SE}=.079, \mathrm{t}(311)=-1.991$, $\mathrm{p}=.047$, as did participants who displayed greater epistemic polarization, $\mathrm{B}=.722$, SE $=.097$, $t(311)=7.484, p<.0001$. The effect for GIHO was not significant, $B=.050, S E=.090, t(311)=$ $.561, p=.575$.

In Model 4, two of the six potential interactions were statistically significant. First, the GIHS by EPG interaction was significant, $B=.267, \mathrm{SE}=.118, \mathrm{t}(305)=2.262, \mathrm{p}=.024$. As seen in 
Figure 1, higher EPG was consistently associated with greater political animosity, which reflects the significant main effect of EPG. But, notably, IH was associated with lower political animosity among participants who scored lower in EPG but not among participants who scored higher in EPG.

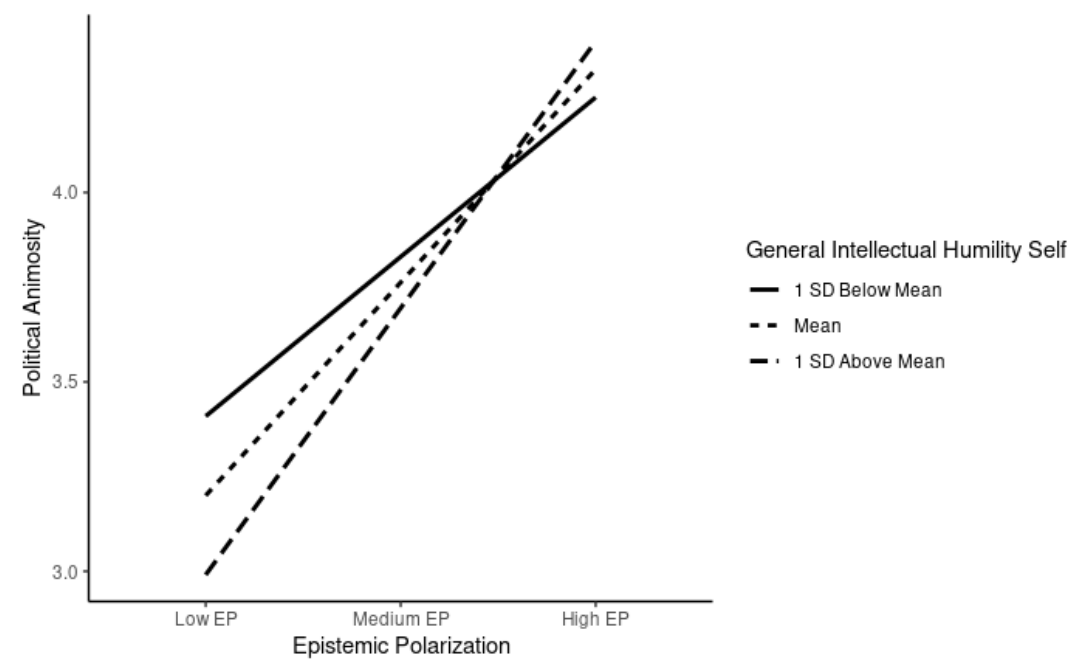

Figure 1. Interaction of GIHS and EPG on Political animosity

In addition, the significant interaction of VH by SIHO clearly supports our hypothesis, B = $-.238, \mathrm{SE}=.100, \mathrm{t}(305)=-2.375, \mathrm{P}=.018$. As seen in Figure 2 , the greatest political animosity was observed among participants who highly valued humility and also perceived contrapartisans to be low in IH with respect to political issues. In contrast, the lowest political animosity was observed among participants who highly valued humility and perceived contrapartisans to be high in $\mathrm{IH}$ with respect to politics. Participants who were average in $\mathrm{VH}$ show a similar pattern, though weaker. Interestingly, participants who did not particularly value humility expressed greater political animosity when they thought contrapartisans were high in IH. 


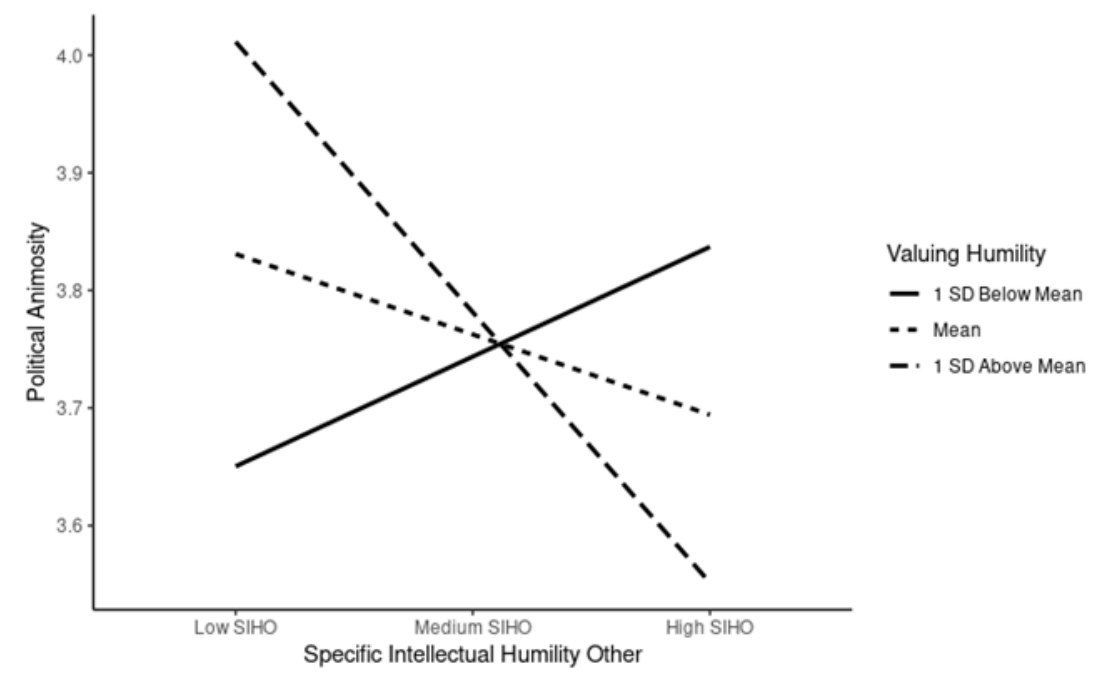

Figure 2. Interaction of VH and SIHO on Political Animosity

\subsection{Discussion}

Our hypothesis leading into Study 2 was that a combination of valuing humility and viewing contrapartisans as low in $\mathrm{IH}$ may partly explain why the relationship between $\mathrm{IH}$ and polarization is weaker than we expected. We tested this notion by developing new measures of epistemic polarization (GIHO, SIHO, and EPG). We were not sure which assessment strategy would be best, so we cast a broad net that measured epistemic polarization in different ways. In the final analysis, we came up with three indices of epistemic polarization and found that two of these measures-SIHO and EPG—-played a role in predicting political animosity.

Our findings exposed a troublesome irony: Although one would assume that leading people to value IH should be a useful antidote to political polarization, our results showed that political animosity was greater among participants who most strongly valued $\mathrm{IH}-$ if they perceived that contrapartisans were low in $\mathrm{IH}$. This finding suggests that simply getting people to value IH may backfire unless they are also convinced that contrapartisans are no less 
intellectually humble than copartisans. Fortunately, research shows that liberals and conservatives do not differ systematically in IH or belief superiority, although they do differ in the issues about which they are each less intellectually humble (Leary et al., 2017; Toner, Leary, Asher, \& Jongman-Sereno, 2013). Perhaps informing people of such results will lower perceived epistemic polarization and political animosity.

\section{General Discussion}

National surveys make it clear that polarization has been getting worse. This has wide ranging implications given that polarization not only negatively impacts political discourse and politics more generally, but it can also affect our relationships with neighbors, romantic partners, coworkers, friends, and family members (lyengar et al., 2019). Compounding the pressures of social identity and homophily, polarization drives us towards people "like us" and away from people "not like us" (Huber \& Malhotra, 2017). On any account, polarization is a multi-faceted problem with no obvious, simple solutions.

The avenue of research we pursued examined the possibility that IH might be useful for stemming the tide of polarization. After all, people who are highly polarized tend to approach attitudes with arrogance and dogmatism that are at loggerheads with the traits of the intellectually humble. However, the relationship between $\mathrm{IH}$ and polarization was more complicated (and more interesting) than we expected. In our attempts to make sense of our preliminary findings, we hypothesized that people who both value humility and derogate the intellectual virtues of contrapartisans may be more likely to be affectively polarized. In exploring this issue, we developed new measures for epistemic polarization that we hope will be useful to researchers moving forward. 
Our studies had several limitations. First, we used only online participants. And while the research we cited earlier suggests that MTurk participants are more diverse than convenience samples drawn from universities, it would be informative to collect data in the laboratory where participants can be monitored more carefully. Second, and more importantly, MTurk participants tend to be less conservative than the general population (Levay, Freese, \& Druckman, 2016). Given that our research is on political polarization, we hope to do follow-up work with online samples that include equal numbers of participants who identify as Democrats and Republicans to be certain that our findings hold for members of both groups. Third, we used only participants who are in the United States. While this is common as a first step, it means that we cannot draw any conclusions about the generalizability of our findings, and cross-cultural research is needed. Finally, both of our studies were correlational. Now that we have new measures for epistemic polarization, we plan to run behavioral studies that experimentally manipulate the constructs that we're interested in-valuing humility, epistemic polarization, affective polarization, etc.

Despite these limitations, we believe that we have made a valuable contribution to our understanding of polarization. While polarization is usually explored as a uniform construct, our findings suggest that it might make sense to focus attention on its constitutive elements such as epistemic polarization and moral polarization. If we're right that valuing humility coupled with epistemic polarization plays an important role in polarization, then it is not just that contrapartisans are judged negatively for the content of their moral and political beliefs but that they are also judged negatively for the epistemic attitudes they bring to bear on these beliefs. 
Shedding further light on the complex relationship between these two related facets of polarization is a task for another day. ${ }^{16}$

\section{References}

Baron, R. M., \& Kenny, D. A. (1986). The moderator-mediator variable distinction in social psychological research: Conceptual, strategic, and statistical considerations. Journal of Personality and Social Psychology, 51(6), 1173-1182.

Brandt, M. J., Reyna, C., Chambers, J. R., Crawford, J. T., \& Wetherell, G. (2014). The Ideological Conflict Hypothesis: Intolerance among both liberals and conservatives. Current Directions in Psychological Science, 23(1), 27-34.

Burhmester, M., Kwang, T., and Gosling, S. (2011). Amazon's Mechanical Turk: A new source of inexpensive, yet high-quality data? Perspectives on Psychological Science, 6, 3-5.

Campbell, A., Converse, P. E., Miller, W. E., \& Stokes, D. (1960). The American voter: Unabridged edition. New York: Wiley.

Church, I. M., \& Barrett, J. L. (2017). Intellectual humility. In E. L. Worthington, Jr., D. E. Davis, \& J.N. Hook (Eds.), Handbook of intellectual humility (pp. 62-75). New York: Routledge.

Clifford, S. (2019). How emotional frames moralize and polarize political attitudes. Political Psychology, 40(1), 75-91.

Crawford, J. T., Brandt, M. J., Inbar, Y., Chambers, J. R., \& Motyl, M. (2017). Social and economic ideologies differentially predict prejudice across the political spectrum, but social issues are most divisive. Journal of Personality and Social Psychology, 112(3), 383-412.

Crockett, M. J. (2017). Moral outrage in the digital age. Nature Human Behaviour, 1(11), 769.

Deffler, S., Leary, M. R., \& Hoyle, R. H. (2016). Knowing what you know: Intellectual humility and judgments of recognition memory. Personality and Individual Differences, 96, 255-259.

Gift, K., \& Gift, T. (2015). Does politics influence hiring? Evidence from a randomized experiment. Political Behavior, 37(3), 653-675.

Hare, S. (1996). The paradox of moral humility. American Philosophical Quarterly, 33(2), 235-241.

Hook, J. N., Farrell, J. E., Johnson, K. A., Van Tongeren, D. R., Davis, D. E., \& Aten, J. D. (2017). Intellectual humility and religious tolerance. Journal of Positive Psychology, 12, 29-35.

Hopkin, C. R., Hoyle, R. H., \& Toner, K. (2014). Intellectual humility and reactions to opinions about religious beliefs. Journal of Psychology and Theology, 42, 50-61.

\footnotetext{
${ }^{16}$ We would like to thank Alessandra Tanesini for very helpful comments on an earlier draft of this chapter.
} 
Hoyle, R. H., Davisson, E. K., Diebels, K. J., \& Leary, M. R. (2016). Holding specific views with humility: Conceptualization and measurement of specific intellectual humility. Personality and Individual Differences, 97, 165-172.

Huber, M., Van Boven, L., Park, B., Pizzi, W. T. (2015). Seeing red: Anger increases how much Republican identification predicts partisan attitudes and perceived polarization. PLOS ONE. Available online at: https://doi.org/10.1371/journal.pone.0139193

Huber, G. A., \& Malhotra, N. (2017). Political homophily in social relationships: Evidence from online dating behavior. The Journal of Politics, 79(1), 269-283.

lyengar, S., Sood, G., \& Lelkes, Y. (2012). Affect, not ideology: A social identity perspective on polarization. Public Opinion Quarterly, 76(3), 405-431.

lyengar, S., Lelkes, Y., Levendusky, M., Malhotra, N., \& Westwood, S. J. (2019). The origins and causes of affective polarization in the United States. Annual Review of Political Science, 22(1), 129-146.

lyengar, S., \& Westwood, S. J. (2015). Fear and loathing across party lines: New evidence on group polarization. American Journal of Political Science, 59(3), 690-707.

Krumrei-Mancuso, E. J. (2017). Intellectual humility and prosocial values: Direct and mediated effects. Journal of Positive Psychology, 12, 13-28.

Krumrei-Mancuso, E. J. (2018). Intellectual humility's links to religion and spirituality and the role of authoritarianism. Personality and Individual Differences, 130, 65-75.

Krumrei-Mancuso, E. J., \& Rouse, S. V. (2015). The development and validation of the Comprehensive Intellectual Humility Scale. Journal of Personality Assessment, 98, 209-221.

Leary, M. The psychology of intellectual humility. https://www.templeton.org/wpcontent/uploads/2018/11/Intellectual-Humility-Leary-FullLength-Final.pdf

Leary, M. R., Diebels, K. J., Davisson, E. K., Jongman-Sereno, K. P., Isherwood, J. C., Raimi, K. T., Deffler, S.A., \& Hoyle, R. (2017). Cognitive and interpersonal features of intellectual humility. Personality and Social Psychology Bulletin, 43(6), 793-813.

Lelkes, Y., Sood, G., \& lyengar, S. (2017). The hostile audience: The effect of access to broadband internet on partisan affect. American Journal of Political Science, 61(1), 5-20.

Levay, K. E., Freese, J., \& Druckman, J. N. (2016). The demographic and political composition of Mechanical Turk samples. SAGE One, January-March, 1-17.

Litman, J. A., \& Spielberger, C. D. (2003). The measurement of epistemic curiosity and its diversive and specific components. Journal of Personality Assessment, 80, 75-86.

Lynch, M. P. (2019). Know-it-all society: Truth and arrogance in political culture. New York: Liveright Publishing. 
McConnell, C., Malhotra, N., Margalit, Y., \& Levendusky, M. (2018).The economic consequences of partisanship in a polarized era. American Journal of Political Science, 62(1), 5-18.

McElroy, S. E., Rice, K. G., Davis, D. E., Hook, J. N., Hill, P. C., Worthington, E, L., Jr., \& Van Tongeren, D. R. (2014). Intellectual humility: Scale development and theoretical elaborations in the context of religious leadership. Journal of Psychology and Theology, 42, 19-30.

Nadelhoffer, T. Wright, J., Echols, M., Perini, T., \& Venezia, K. (2017). Some varieties of humility worth wanting. The Journal of Moral Philosophy, 14(2), 168-200.

Paolacci, G., Chandler, J., and Ipeirotis, P. (2010). Running experiments on Amazon Mechanical Turk. Judgment and Decision Making, 5, 411-419.

Pariser, E. (2011). The filter bubble: How the new personalized web is changing what we read and how we think. New York: Penguin Books.

Pew Research Center. (2014) Political polarization in the American public. Technical report. Available online at: www.people-press.org/2014/06/12/political-polarization-in-the-american public/

Pew Research Center. (2016). Partisanship and political animosity in 2016. Technical report. Available online at: www.people-press.org/2016/06/22/partisanship-and-political-animosity-in$\underline{2016 /}$

Pew Research Center. (2017). The partisan divide on political values grows even wider. Technical report. Available online at: www.people-press.org/2017/10/05/the-partisan-divide-on-politicalvalues-grows-even-wider/

Porter, T., \& Schumann, K. (2018). Intellectual humility and openness to the opposing view. Self and Identity, 17(2), 139-162.

Rand, G. (2012). The promise of Mechanical Turk: How online labor markets can help theorists run behavioral experiments. Journal of Theoretical Biology, 299, 172-179.

Samuelson, P. L., Church, I. M., Jarvinen, M., \& Paulus, T. (2012). The science of intellectual humility white paper. Unpublished manuscript, School of Psychology, Fuller Theological Seminary, Pasadena, California.

Saucier, D. A., \& Webster, R. J. (2010). Social vigilantism: Measuring individual differences in belief superiority and resistance to persuasion. Personality and Social Psychology Bulletin, 36(1), 19-32.

Sunstein, C. (2001). Echo chambers, Bush v. Gore, impeachment, and beyond. Princeton, NJ: Princeton University Press. 
Tajfel, H. (1978). Differentiation between social groups: Studies in the social psychology of intergroup relations. London: Academic Press.

Tajfel, H. (1981). Human groups and social categories. Cambridge, UK: Cambridge University Press.

Tajfel, H. (1982). Social psychology of intergroup relations. Annual Review of Psychology, 33(1), 1-39.

Tajfel, H., \& Turner, J. (1979). An integrative theory of intergroup conflict. In W.G. Austin \& S. Worchel (Eds), The social psychology of intergroup relations (pp. 33-47). Monterey, CA: Brooks Cole.

Toner, K. E., Leary, M. R., Asher, M., \& Jongman-Sereno, K. P. (2013). Feeling superior is a bipartisan issue: Extremity (not direction) of political views predicts perceived belief superiority. Psychological Science, 24, 2454-2462.

Van Tongeren, D. R., Stafford, J., Hook, J. N., Green, J. D., Davis, D. E., \& Johnson, K. A. (2016). Humility attenuates negative attitudes and behaviors toward religious outgroup members. Journal of Positive Psychology, 11, 199-208.

Weisberg, H.F., \& Rusk, J.G. (1970). Dimensions of candidate evaluation. American Political Science Review, 64 (4), 1167-1185.

Whitcomb, D., Battaly, H., Baehr, J., \& Howard-Snyder, D. (2015). Intellectual humility: Owning our limitations. Philosophy and Phenomenological Research, 94(3), 509-539.

Wright, J., \& Nadelhoffer, T., Ross, L., \& Sinnott-Armstrong, W. (2017). Be it ever so humble: An updated account and scale for humility. Self and Identity, 17(1), 92-125.

Zhang, H., Farrell, J. E., Hook, J. N., Davis, D. E., Van Tongeren, D. R., \& Johnson, K. A. (2015). Intellectual humility and forgiveness of religious conflict. Journal of Psychology and Religion, 43, 255-262. 